\title{
Influence of different wet milling on the properties of an attapulgite clay, contribution of inverse gas chromatography
}

\author{
Lilya Boudriche $^{\mathrm{a}, \mathrm{b}, *}$, Rachel Calvet $^{\mathrm{c}}$, Alain Chamayou ${ }^{\mathrm{c}}$, Boualem Hamdi ${ }^{\mathrm{b}}$ \\ a Centre de Recherche Scientifique et Technique en Analyses Physico-Chimiques, BP 384 Bou-Ismail, RP 42004 Tipaza, Algeria \\ b Laboratoire d'études physico-Chimiques des matériaux et Applications à l'Environnement, Faculté de Chimie, USTHB, BP 32 El Alia, Bab Ezzouar, 16111 Alger, Algeria \\ ${ }^{c}$ Université de Toulouse, IMT Mines Albi, CNRS, Centre RAPSODEE, Campus Jarlard, F-81013 Albi cedex 09, France
}

\section{Keywords:}

Attapulgite

Clay

Wet grinding

Surface properties

Inverse gas chromatography

\section{A B S T R A C T}

An experimental study, using size measurements, X-ray diffraction (XRD), scanning electron microscopy (SEM) and inverse gas chromatography at infinite dilution (IGC-ID) and finite concentration (IGC-FC) conditions, has been carried out to evaluate, respectively, the changes of particles size, crystalline phases, morphology and surface properties evolution of attapulgite powder after grinding in wet media.

The particles size decreases significantly after grinding in ball mill in different liquid media. The SEM analysis shows that the fibers are preserved during grinding in aqueous media. With IGC-ID, after grinding using wet ball milling in hydrochloric acid, the values of $\gamma_{s}^{\mathrm{d}}$ determined by injection of alkane probes decrease significantly because of the disappearance of the insertion sites able to retain the probes. In the same grinding conditions, with IGC-FC, the specific surface area obtained with octane probe increases significantly from $114 \mathrm{~m}^{2} / \mathrm{g}$ to $156 \mathrm{~m}^{2} / \mathrm{g}$.

\section{Introduction}

Because of the abundance of clays on the earth's surface and due to their ability to undergo transformations in different ways [1-4], these solids are involved in many applications: pharmaceuticals, petroleum, chemical, wastewater treatment, catalysis, ...etc. [5-8].

The use of grinding processes in the mineral industry is very common in order to reduce the particles size. However, grinding generally induces fragmentation of the original particles and changes in the morphology creating new surfaces, that can affect the behavior of the solid in later steps of the process (granulation, compaction, etc.) and that can influence the end-use properties of the final product. Compared to dry milling, wet milling is very often carried out, since it has some advantages [9], such as avoiding the formation of dust and limiting the agglomeration of fine particles. This type of grinding processes allows better energy efficiency, thanks to the combination of two types of constraints, compressive stresses between two solid surfaces, and shear stresses due to the environment.

Thus, the knowledge and control of the surface characteristics of solids such as the nature and distribution of chemical groups, surface energy and morphology are essential for understanding and

* Corresponding author at: Centre de Recherche Scientifique et Technique en Analyses Physico-Chimiques, BP 384 Bou-Ismail, RP 42004 Tipaza, Algeria.

E-mail address: boudriche.lilya@gmail.com (L. Boudriche). predicting their behavior when they are in contact with gases, liquids or other solids.

In this work, the variation of different characteristics of an attapulgite clay (ie. particle size, morphology, mineralogical properties and surface properties) after wet grinding has been monitored according to different grinding times and different liquid grinding media. The choice of organic and inorganic solvents used in this study was motivated by previous studies on chrysotile [10], muscovite [11] and sepiolite [12].

The physicochemical aspects of grinding and more particularly the role of grinding on the evolution of the surface properties of the divided solids after application of mechanical stresses were evaluated in previous studies by inverse gas chromatography at infinite dilution (IGCID) [13] and finite concentration (IGC-FC) [14]. As demonstrated in several studies [15-17], inverse gas chromatography appears as a practical and useful method for the evaluation of changes (morphology and surface heterogeneity) under mechanical stress.

\section{Experimental part}

\subsection{Materials}

Attapulgite (or palygorskite) used in this work was extracted from Ghoufi's region, at the North-East of Algeria. This fibrous clay is a hydrated octahedral magnesium aluminum silicate mineral [18-20]. 
Two kinds of solvents were considered in this study, organic solvents such as: ethanol (Fluka, $\geq 99.8 \%$ ), toluene (Fluka, $\geq 99.5 \%$ ) and inorganic solvents: distilled water, a solution of $\mathrm{HCl} 0.5 \mathrm{M}$ (Prolabo, 38\%) and a solution of $1 \mathrm{M} \mathrm{KCl}$ (Fluka, $\geq 99 \%$ ).

\subsection{Wet grinding conditions}

Different liquids media implementing solvents with various solubility parameters have been used in this study. The grinding experiments were carried out in a ball mill, MARNE 1 type, provided by the FAURE equipment company. This device was already used in a previous study [21] in dry way, in this study the wet way has been tested. According to the supplier's recommendations, the $1 \mathrm{~L}$ jars (Internal diameter estimated at $116 \mathrm{~mm}$ ) were filled with $1 \mathrm{~kg}$ of ceramic balls $\left(\rho_{\text {solid }}=\right.$ $3510 \mathrm{~kg} / \mathrm{m}^{3}$ ) with different diameters (20\% of $24 \mathrm{~mm}$ in diameter, $20 \%$ of $19 \mathrm{~mm}$ and $60 \%$ of $12 \mathrm{~mm}$ ). The rotation speed of the containers has been set at $70 \mathrm{rpm}$. This relatively low operating rotation speed correspond to $50 \%$ of the critical rotation speed (139 rpm). In this case, it seems reasonable to assume a motion in cascading regime.

An amount of $30 \mathrm{~g}$ of $1 \mathrm{~mm}$ sieved powder is put into the jar with $300 \mathrm{~cm}^{3}$ of solvent as a grinding medium.

The grinding time of $3 \mathrm{~h}$ was fixed for each medium. In water, experiments with $3 \mathrm{~h}, 8 \mathrm{~h}$ and $30 \mathrm{~h}$ of grinding were carried out.

\subsection{Characterization methods}

Particle size distribution measurements were performed using a laser diffraction method on a Malvern Mastersizer 2000 device. The samples were analyzed using a wet-way feeder (Hydro, Malvern) with water. Different characteristic diameters for particle size distribution were obained such as the equivalent diameters of attapulgite particles $d_{10}, d_{50}, d_{90}$ as well as the mean value diameter $d_{43}$, the Sauter or mean surface/volume diameter $\mathrm{d}_{32}$, and the Span value as described in the following equation: $\operatorname{Span}=\left(\mathrm{d}_{90}-\mathrm{d}_{10}\right) / \mathrm{d}_{50}$, characterize the spreading of the particle size distribution around the median value $\left(\mathrm{d}_{50}\right)$. According to the evolution of the values, it may give indications on the size reduction mechanism.

Particle morphology was investigated using a scanning electron microscope (Philips XL 30 model ESEM-FEG) operating at $3 \mathrm{kV}$.

Phase identification was performed on a Panalytical X'PERT Pro diffractometer (Philips) (CuK $\alpha$ radiation) with a step size of $0.017^{\circ}$ for $2 \theta$ angles ranging from $5^{\circ}$ to $80^{\circ}$. The $2 \theta$ values were analyzed with the X'Pert High Score software and compared with the ICDD (International Centre for Diffraction Data) database.

The BET specific surface areas, BET constants, meso- and micropore volumes were determined using nitrogen adsorption at $77 \mathrm{~K}$ (ASAP 2010, Micromeritics) by applying the BET, BJH, and t-plot methods. The samples were out gassed before analysis, at $105^{\circ} \mathrm{C}$ for $24 \mathrm{~h}$ at a pressure of $8.10^{-3}$ mbar.

Wettability measurement (contact angles), of organics liquids (ethanol and toluene) on attapulgite surface before and after grinding, were carried out by means of an ILMS device of the company GBX. The tests were performed on initial attapulgite powder before and after compression. The tablets were made using a branded uniaxial powder press (Instron Press 5567) at a pressure of $10 \mathrm{kN}$ and at room temperature. One drop $(10 \mu \mathrm{L})$ of the solvent considered is deposited on the surface of the attapulgite tablet. Its evolution according to the time has been recorded.

The determination of the iron, aluminum, magnesium and silicon elements was carried out after mineralization by alkaline fusion with lithium tetra-borate, using an inductively coupled plasma (ICP) apparatus, type 3580, from the Thermo Fisher Company. For the determination of potassium and calcium elements, mineralization was carried out after by treatment of the samples with $\mathrm{HF}, \mathrm{HClO}_{4}, \mathrm{HNO}_{3}$ then brought to dryness and taken up in $\mathrm{HNO}_{3}$ solution.
The IGC measurements were performed with two GC devices (Agilent $7890 \mathrm{~A}$ and 6890), fitted with sensitive flame ionization detectors (FID). Helium was used as carrier gas with a flow rate of $30 \mathrm{~mL} / \mathrm{min}$ measured with an electronic flow meter (Flow500-Agilent). The injector and detector temperatures were $130{ }^{\circ} \mathrm{C}$ and $200{ }^{\circ} \mathrm{C}$, respectively. The columns were filled with a mixture of attapulgite powder and glass beads. The amount of powder in the column was chosen according to the pressure drop, which had to be lower than 1 bar in order to avoid leaks at the septum and fittings.

The IGC-ID study was performed at an oven temperature of $130{ }^{\circ} \mathrm{C}$, using stainless steel columns of $20 \mathrm{~cm}$ length and $6.35 \mathrm{~mm}$ internal diameter.

The columns were conditioned overnight at $150^{\circ} \mathrm{C}$, and the analyses were carried out at $130^{\circ} \mathrm{C}$. It should be noted that up to $150^{\circ} \mathrm{C}$., the surface properties of the attapulgite powder remain unchanged.

The probes used were linear alkanes, hexane (C6), heptane (C7) and octane (C8), cyclic and branched alkanes, cyclooctane (Cycl8), 2,3,4triméthylpentane (2,3,4TMP) and 2,5-dimethylhexane (2,5-DMH), and polar probes, chloroform $\left(\mathrm{CHCl}_{3}\right)$, and dichloromethane, $\left(\mathrm{CH}_{2} \mathrm{Cl}_{2}\right)$. These probes were of chromatographic grade (99\%) purity.

For IGC-FC, the chromatographic columns were $10 \mathrm{~cm}$ in length and $6.35 \mathrm{~mm}$ or $3.18 \mathrm{~mm}$ in internal diameter. The conditioning temperature was $150{ }^{\circ} \mathrm{C}$. Analysis temperature depended on the probe used, according to the Conder criterion [22]. This criterion states that the contribution of probe vapors to the flow of carrier gas should not exceed $5 \%$ of the initial flow at the maximum of the chromatographic peak. Two probes were examined by IGC-FC, octane (C8) at $53^{\circ} \mathrm{C}$ and isopropanol (IP) at $43{ }^{\circ} \mathrm{C}$. A non-polar probe, octane, was chosen to study surface morphology and a polar probe, isopropanol, to examine the surface chemistry of ground samples.

Morphological, mineralogical and surface properties were determined after drying of the milled powder in wet media.

\section{Results and discussion}

The particle size, surface properties, mineralogical and morphological structure modifications, induced after wet grinding were assessed.

\subsection{Particle size analysis}

Fig. 1 shows the changes in particle size distribution obtained by laser granulometry in the liquid way, in water, after grinding of attapulgite in the ball mill in several liquid media, such as, ethanol, toluene, hydrochloric acid $(0.5 \mathrm{M})$, potassium chloride $(1 \mathrm{M})$ and distilled water.

The particle size distributions indicate that grinding in liquid medium in the ball mill is more efficient than grinding in dry conditions [21]. After $3 \mathrm{~h}$ of grinding in the various environments, the comminution process makes it possible to reduce the size of the particles resulting in the formation of two populations, one is around $10 \mu \mathrm{m}$ and the other much thinner $(<1 \mu \mathrm{m})$ but much smaller in volume than the first one. This last population increases after $30 \mathrm{~h}$ of grinding (Fig. 1d).

In Table 1 are gathered the characteristic diameters of attapulgite particle size before and after grinding such as the $d_{10}, d_{50}, d_{90}$ as well as the mean volume diameter $d_{4 / 3}$, the Sauter or mean surface/volume diameter $\mathrm{d}_{3 / 2}$, and the Span values.

No effects were observed on the equivalent diameter values $d_{10}, d_{50}$, $\mathrm{d}_{90}$ whatever the grinding medium and they remains almost similar after $3 \mathrm{~h}$ of grinding. The constancy in the values of equivalent diameters observed after $3 \mathrm{~h}$ of grinding in the different liquid media can be due to the time of grinding which appears insufficient to highlight a notable variation in the evolution of the size of the attapulgite particles after grinding. Only a variation of the operating conditions used in the ball mill (load and dimensions of the grinding body, grinding speed) 
(a)

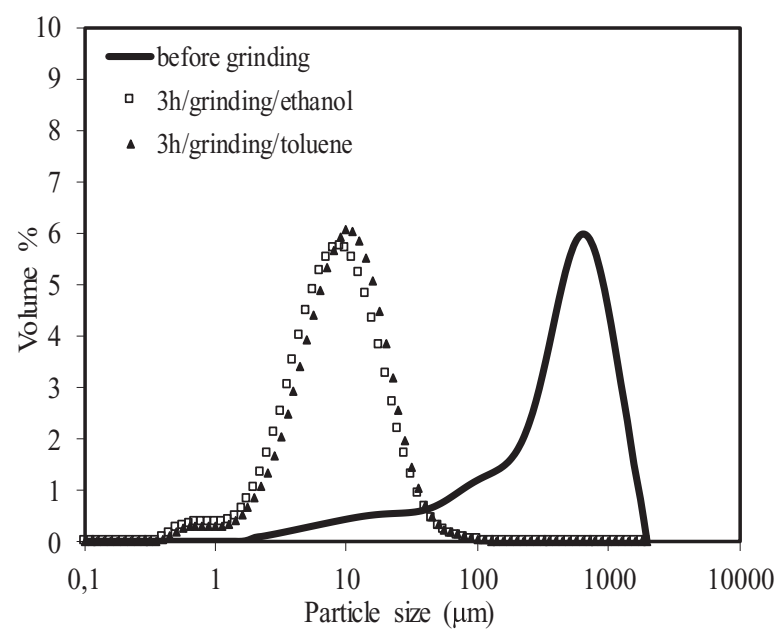

(b)

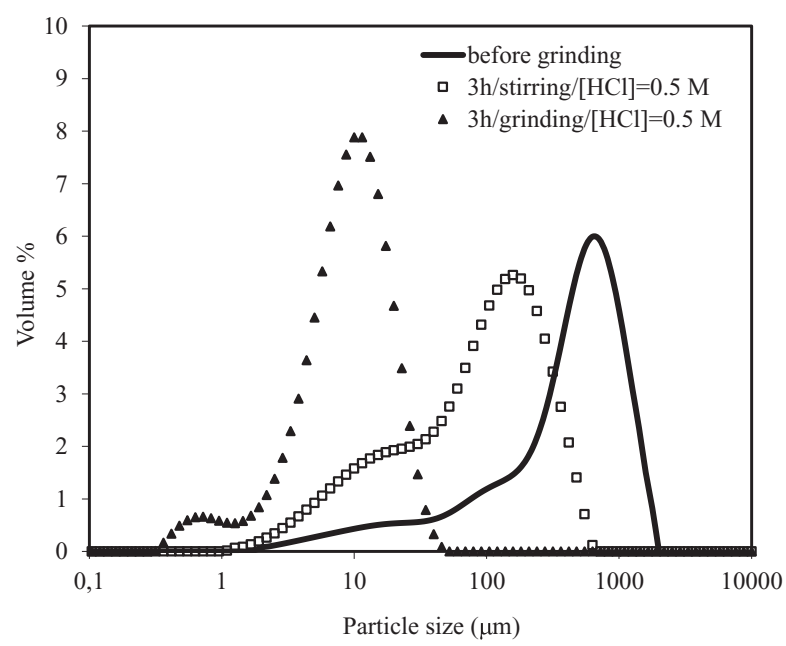

Fig. 1. Particle size distributions of attapulgite ground in the ball mill in different media: (a) ethanol and toluene, (b) hydrochloric acid solution ( $0.5 \mathrm{M})$ after stirring in an acidic solution, (c) $\mathrm{KCl}$ solution (1 M), and (d) water at various grinding times.

or an extension of the grinding time can make it possible to achieve a higher milling efficiency reflected by finer particle sizes.

For all experiments with $3 \mathrm{~h}$ grinding time, the span values are similar (around 2.00) indicating a similar spreading of particles size, in the different liquid media. After $8 \mathrm{~h}$ and $30 \mathrm{~h}$ of grinding in water, the particle size distribution is relatively spread as shown by the value of the span indicating the formation of very fine particules (around $1 \mu \mathrm{m}$ ). Moreover, this new population of particles increases the difference between $\mathrm{d}_{43}$ and $\mathrm{d}_{32}$.

Moreover, the stirring of attapulgite in acid medium (without grinding) did not achieve fine particle sizes values such as grinding in the same medium. The acid environment is not sufficient to explain the size reduction.

\subsection{Morphological and microstructure analysis}

Fig. 2 shows the morphology of attapulgite, before and after grinding, in various liquid media.

Before grinding, the microstructure SEM analysis of attapulgite indicates a fibrous morphology (Fig. 2.a1), with a length not exceeding $3 \mu \mathrm{m}$. The presence of cubic forms inserted in the fibers was also observed (Fig. 2.a2). The $\mathrm{X}$ analysis of these cubic crystals confirms the (c)



(d)

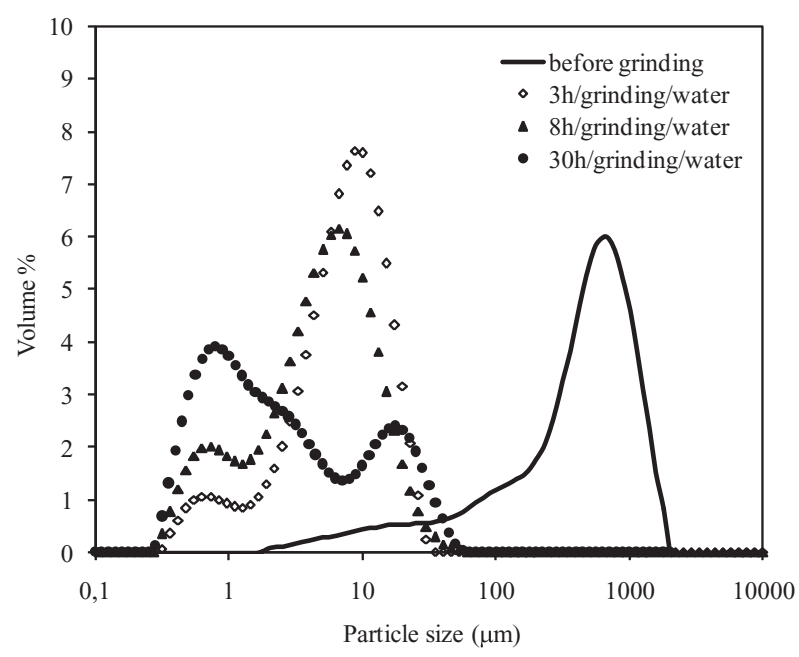

Fig. 1 (continued).

majority presence of four elements, Ca (22.38\%), C (18.48\%) and O (44.76\%) and $\mathrm{Mg}$ (13.32\%) relating to the carbonated impurities.

Unlike in dry grinding [21], the micrographs after grinding in different liquid media suggests that attapulgite fibers are preserved, in particular in water, despite the fineness of the particles obtained after $30 \mathrm{~h}$ of grinding. The liquid medias used with these grinding operating conditions, seems to act as lubricant or shield towards mechanical stresses.

The same observation was made after SEM analysis of chrysotile (asbestos) milled in water [15], the fibers were maintained up to $48 \mathrm{~h}$ of grinding, while for the same grinding time in toluene a total amorphization of chrysotile fibers was obtained.

Another study [12] conducted on a sepiolite, milled in liquid process, caused the appearance of flakes with a length of 5 to $15 \mu \mathrm{m}$. The micrography showed that the formed flakes were actually agglomerates of fibers. When these flakes were dispersed in a solution with very vigorous stirring, the micromorphology of the initial sepiolite reappeared. In summary, the fibrous morphology was preserved even after a long grinding in water.

The sample milled in the ball mill in a $0.5 \mathrm{M}$ hydrochloric acid solution (Fig. 2.d1) retains the fibrous structure, but surface roughness appears on the cubic forms, initially observed in the fibrous network and attributed to carbonates (Fig. 2.d2). 
Table 1

Main characteristic diameters of the attapulgite particles before and after wet-grinding (The particle size measurements are carried out in liquid way).

\begin{tabular}{|c|c|c|c|c|c|c|c|}
\hline & $\begin{array}{l}\text { Grinding } \\
\text { time/media }\end{array}$ & $\begin{array}{l}\mathrm{d}_{10} \\
(\mu \mathrm{m})\end{array}$ & $\begin{array}{l}\mathrm{d}_{50} \\
(\mu \mathrm{m})\end{array}$ & $\begin{array}{l}\mathrm{d}_{90} \\
(\mu \mathrm{m})\end{array}$ & $\begin{array}{l}\mathrm{d}_{43} \\
(\mu \mathrm{m})\end{array}$ & $\begin{array}{l}\mathrm{d}_{32} \\
(\mu \mathrm{m})\end{array}$ & Span \\
\hline \multicolumn{2}{|c|}{ Before grinding } & 34 & 502 & 1162 & 558.21 & 67.17 & 2.24 \\
\hline \multirow{2}{*}{$\begin{array}{l}\text { Organic } \\
\text { media }\end{array}$} & $3 \mathrm{~h} /$ ethanol & 3 & 9 & 23 & 11.62 & 5.45 & 2.22 \\
\hline & $3 \mathrm{~h} /$ toluene & 3 & 10 & 25 & 12.65 & 6.11 & 2.20 \\
\hline \multirow[t]{6}{*}{$\begin{array}{l}\text { Mineral } \\
\text { media }\end{array}$} & $\begin{array}{l}3 \mathrm{~h} / \mathrm{HCl} \\
0.5 \mathrm{M} / \text { grinding }\end{array}$ & 3 & 10 & 22 & 11.39 & 5.16 & 1.90 \\
\hline & $\begin{array}{l}3 \mathrm{~h} / \mathrm{HCl} \\
0.5 \mathrm{M} / \text { stirring }\end{array}$ & 10 & 103 & 331 & 140.45 & 27.90 & 3.11 \\
\hline & $3 \mathrm{~h} / \mathrm{KCl} 1 \mathrm{M}$ & 2 & 8 & 17 & 8.68 & 3.72 & 1.87 \\
\hline & $3 \mathrm{~h} /$ water & 2 & 8 & 18 & 9.70 & 3.87 & 2.00 \\
\hline & 8 h/water & 0.81 & 5 & 16 & 12.02 & 2.41 & 3.03 \\
\hline & 30 h/water & 0.56 & 2 & 20 & 7.12 & 1.44 & 9.72 \\
\hline
\end{tabular}

\subsection{Mineralogical analysis (XRD)}

From XRD analysis of samples obtained after $3 \mathrm{~h}$ of grinding in a liquid process (Figs. 3 and 4), it seems that the grinding medium (organic or water) does not affect the patterns.

Whatever the grinding solvent, the baseline of the XRD patterns is not affected and intensity of peaks remains relatively unchanged. This persistence proved the stability of attapulgite crystallinity in these grinding media.

After milling in an acid medium (Fig. 5), a carbonate removal can be observed in the XRD patterns. As evidence, the intensities of the peaks attributed to calcite or dolomite decrease until disappearing for some peaks during the grinding in acid medium compared to the raw sample. The semi quantitative XRD was also applied on both samples, original and acid milled attapulgite. On the first one, $13 \%, 14 \%$ and $43 \%$ were obtained respectively for calcite, dolomite and attapulgite. After milling in the acid medium, only the attapulgite cristaline structure remained. Furthermore, the $\mathrm{KCl}$ medium does not alter the crystallinity of the solid.

\subsection{Surface analysis by nitrogen adsorption}

Table 2 shows the values of the specific surface areas and the BET constants determined by nitrogen adsorption and exploitation of the adsorption isotherms obtained on the attapulgite ground in the various media.

All the wet milling except for the acid medium lead to a reduction in the specific surface area and the microporous volume comparatively to the raw attapulgite, which had already been observed during dry milling [21]. The grinding affects the internal structure of the particles through the porous network, by eliminating the microporosity while the mesoporosity increase, knowing that the microporosity is determinant in the variation of the specific surface which decreases.

Grinding in an acid medium leads to an increase of the specific surface area as well as mesoporous and microporous volumes. An experiment with only stirring of the attapulgite was carried out in an acid medium, in other words without the presence of the balls which are at the origin of the mechanical stresses, the aim being to analyze the supply of the grinding for the acidic conditions. The specific surface area obtained also increases, but remains lower than that obtained after grinding in an acid medium. The combination of the acid medium and the mechanical stresses favors the creation of new surfaces caused by the removal of the carbonates as demonstrated by XRD (Fig. 5).

\subsection{Determination of surface properties of the ground samples by IGC}

\subsubsection{Inverse gas chromatography at infinite dilution (IGC-ID)}

The dispersive component of the surface energy $\gamma_{s}^{\mathrm{d}}$, obtained by injections of linear alkanes, has been determined in the different milling media (Table 3). This parameter indicates the ability of the solid surface to have non-specific interactions with probe molecules [23].
In organic media the values of $\gamma_{\mathrm{s}}^{\mathrm{d}}$ decrease after milling, more particularly in ethanol (from $164 \mathrm{~mJ} / \mathrm{m}^{2}$ to $123 \mathrm{~mJ} / \mathrm{m}^{2}$ ). This significant variation is attributed to the disappearance of some active sites able to generate attractive forces with alkane probes.

The nanomorphological index, $I_{M}\left(X_{t}\right)$ gives information about the regularity of the solid surface at the molecular scale, it can be calculated by injections of branched or cyclic alkanes and the value [24]. In this study, the $I_{M}$ parameter obtained by injection of branched (2,3,4-trimethylpentane and 2,5-dimethylhexane) and cyclic (cyclooctane) probes, corroborate the modification of the ground sample in ethanol since its increase confirms the disappearance of the area roughness.

In mineral media, the surface properties of ground attapulgite in the various media (water, $\mathrm{HCl} 0.5 \mathrm{M}$ and $\mathrm{KCl} 1 \mathrm{M}$ ) are somewhat affected by mechanical stresses since it decreases slightly ( $8 \%$ for grinding in $\mathrm{KCl}$ whereas the error is $4 \%$ ).

Grinding in $0.5 \mathrm{M} \mathrm{HCl}$ solution significantly reduces the dispersive component of surface energy from $164 \mathrm{~mJ} / \mathrm{m}^{2}$ to $139 \mathrm{~mJ} / \mathrm{m}^{2}$, indicating a decrease in structural defects that act as insertion sites for alkane probes, confirmed by the small increase in morphological indexes. The value of the dispersive component of the surface energy of stirred sample in an acid medium is identical to that calculated for raw attapulgite, meaning that the combination of mechanical stresses and acidic media is necessary to affect the surface properties of attapulgite.

The specific component of the surface energy $\left(I_{s p}\right)$ can be determined by injections of polar probes, and gives information about the interactions between the probes and the solid surface [13]. The variation of the $I_{s p}$ in this study, remains insignificant whatever for samples ground in organic or mineral media, meaning stability of the surface chemistry of attapulgite during the various grinding processes. In other words, the basic character of the surface area examined by acid probes, chloroform and dichloromethane is not affected by the mechanical stress.

There are very few works reported in the literature on the use of this technique for the study of clays materials with a fibrous structure [25-27]. The only works related to the implementation of the IGC-ID for the evaluation of grinding effect in a liquid medium, concern lamellar phyllosilicates, such as the study of Aouadj [11] which highlighted by means of the IGC, the grinding efficiency of mica muscovite with the addition of organic additives (polyacrylic acid (PAA), (and its oligomers). It has found that in an aqueous medium, polyacrylic acid slows down the kinetics of grinding of mica ensuring some protection of muscovite, whereas $\mathrm{KCl}(1 \mathrm{M})$ and PAA oligomers accelerate it considerably. In IGC-ID, the dispersive component of the surface energy of the mica before grinding is equal to $48 \mathrm{~mJ} / \mathrm{m}^{2}$. This value increases rapidly from the first hours of grinding in $\mathrm{KCl}(1 \mathrm{M})$ and PAA dimer and doubles after $20 \mathrm{~h}$ of grinding. This rapid growth of $\gamma_{s}^{d}$ as a function of the grinding time can be attributed, according to Aouadj, to the appearance of lateral surfaces with more active adsorption sites than the basal surfaces. In another study, Roland [10] applied IGC-ID to monitor the evolution of surface energy of milled muscovite in water and in organic media such as methanol and toluene. The values of the measured $\gamma_{s}^{d}$ at $132{ }^{\circ} \mathrm{C}$, showed appreciable differences for the different muscovite grinding media:

- For the samples obtained in methanol, the values of believe remarkably after a short grinding period, this growth corresponds to the increase of the lateral surfaces.

- For samples milled in water, the values of increase steadily up to $70 \mathrm{~h}$ of grinding.

- For the samples ground in toluene, the values of the display a different behavior since they pass through a maximum after $25 \mathrm{~h}$ of grinding. Beyond 25 h, it decreases sharply. Papirer [15] attributed this 
(a1)

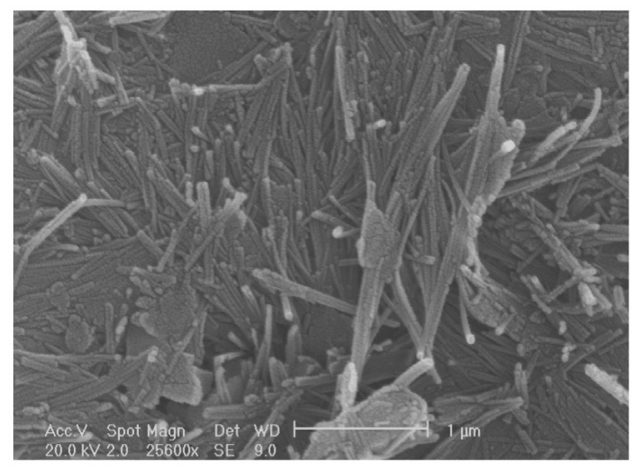

(b)

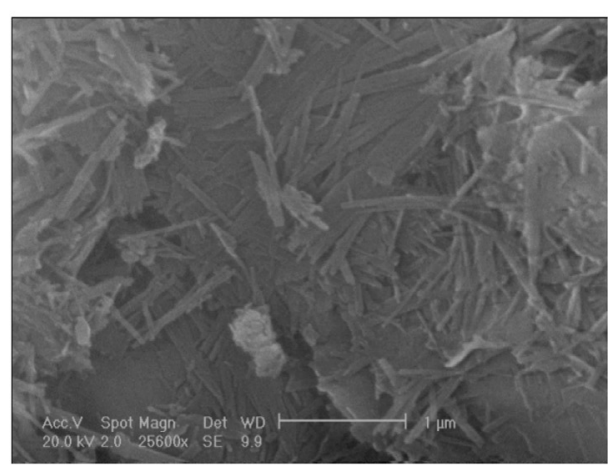

(d1)

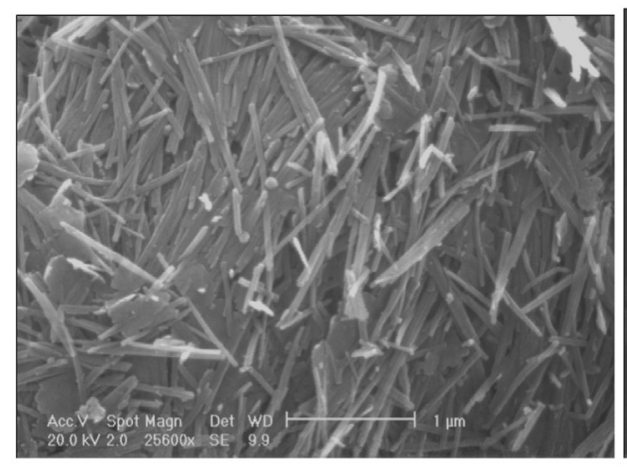

(e)



(a2)

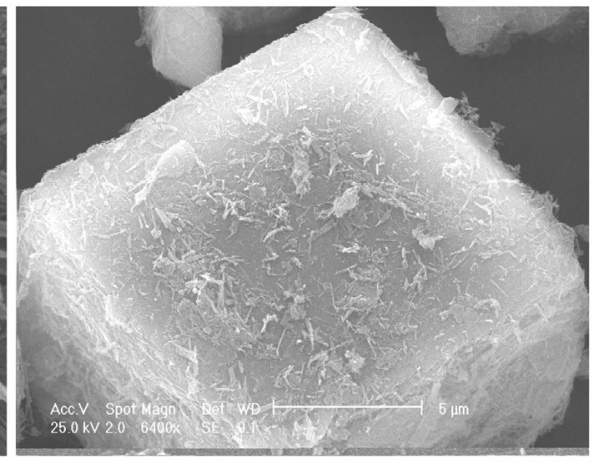

(c)

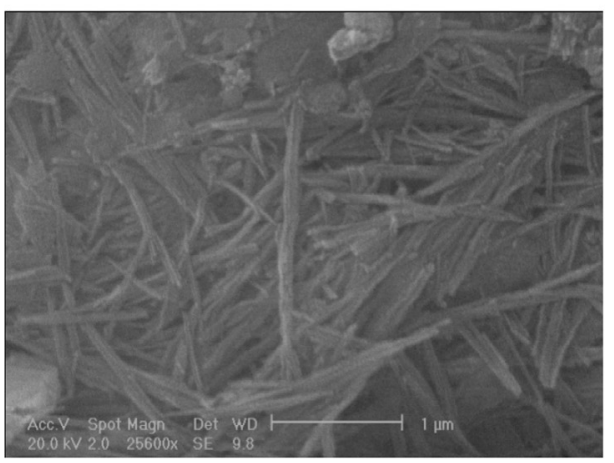

$(\mathrm{d} 2)$



(f)

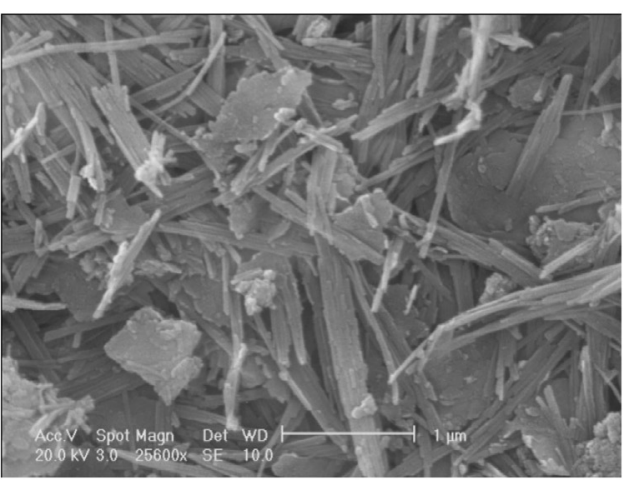

Fig. 2. Attapulgite (a1 and a2) before grinding, (b) after grinding $3 \mathrm{~h}$ in ball mill in toluene, (c) ethanol, (d1 and d2) $0.5 \mathrm{M} \mathrm{HCl}$, (e) $1 \mathrm{M} \mathrm{KCl}$, and (f) $30 \mathrm{~h}$ in water. 


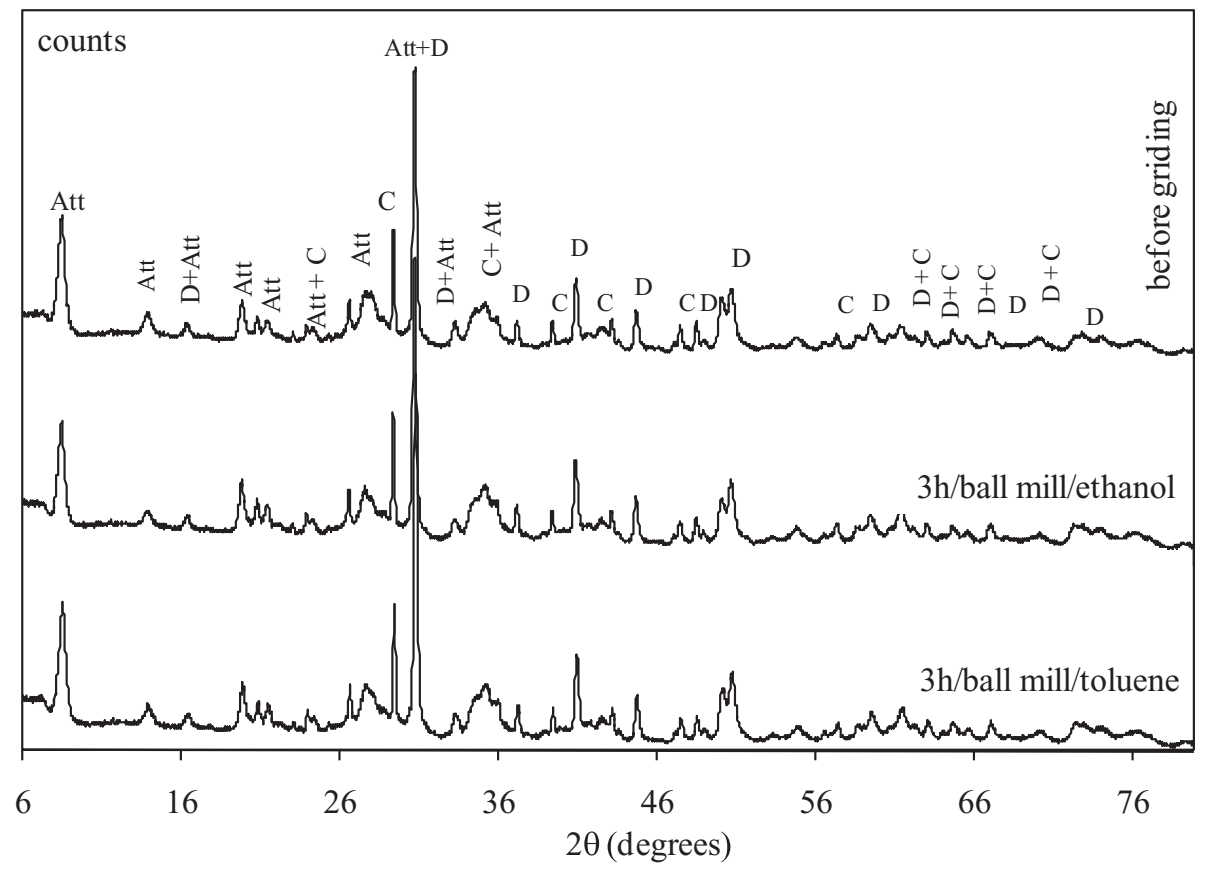

Fig. 3. X-ray diffraction patterns of attapulgite before and after $3 \mathrm{~h}$ of grinding in ball mill, in ethanol and toluene (Att $=$ attapulgite, $\mathrm{C}=\mathrm{calcite}, \mathrm{D}=\mathrm{dolomite})$.

variation to a particle agglomeration phenomenon and the recombination of highly active sites, created during the grinding process.

In the study carried out by Balard [28] on kaolinite grinding in a $1 \mathrm{M}$ $\mathrm{KCl}$ solution, a rapid increase is observed in the values after $30 \mathrm{~h}$ of grinding. At the same time, the values of the morphology index decrease significantly, reflecting the appearance of surface roughness due to the creation of new basal and lateral surfaces.

However, the response provided by an isolated molecule in IGC-ID favors the most energetic sites on the surface. Then, it is necessary to explore the surface at higher coating rates up to the monolayer and the IGC-FC gives us information on all surface of the analyzed sample.

\subsubsection{Inverse gas chromatography at finite concentration (IGC-FC)}

3.5.2.1. Determination of specific surface area. Table 4 lists the values of the specific surface areas and the BET constants determined for octane and isopropanol probes on attapulgite grinded in organic and mineral medium. The nitrogen specific surface areas values are listed for comparative purposes.

3.5.2.1.1. Grinding in organic media. Table 4 shows that the specific surface areas depend on the nature of the probe, whatever the grinding conditions, nitrogen and octane lead to comparable specific surfaces, nevertheless, the values are slightly higher than those measured with isopropanol. Actually, with this last probe, a non-negligible part of

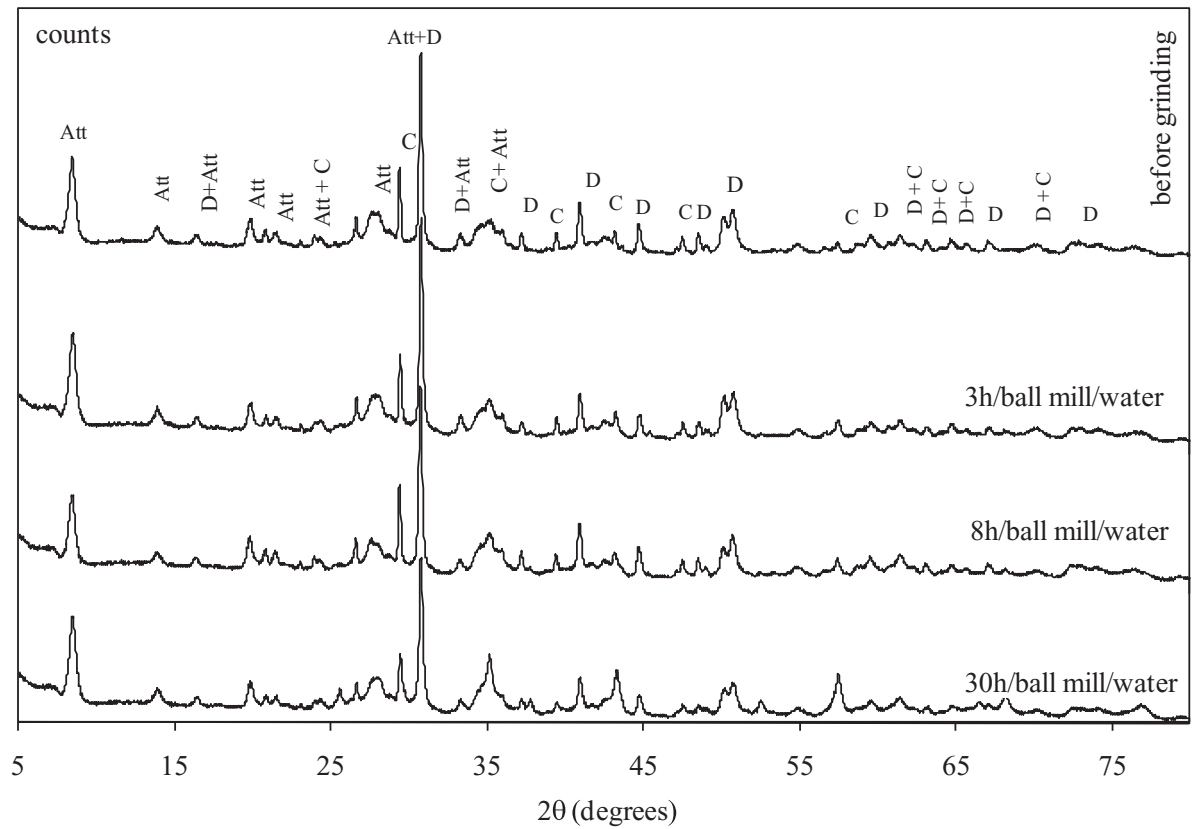

Fig. 4. X-ray diffraction patterns of attapulgite before and after $3 \mathrm{~h}, 8 \mathrm{~h}$ and $30 \mathrm{~h}$ of grinding in ball mill in water (Att $=$ attapulgite, calcite $\mathrm{C}=\mathrm{D}=\mathrm{dolomite}$ ) 


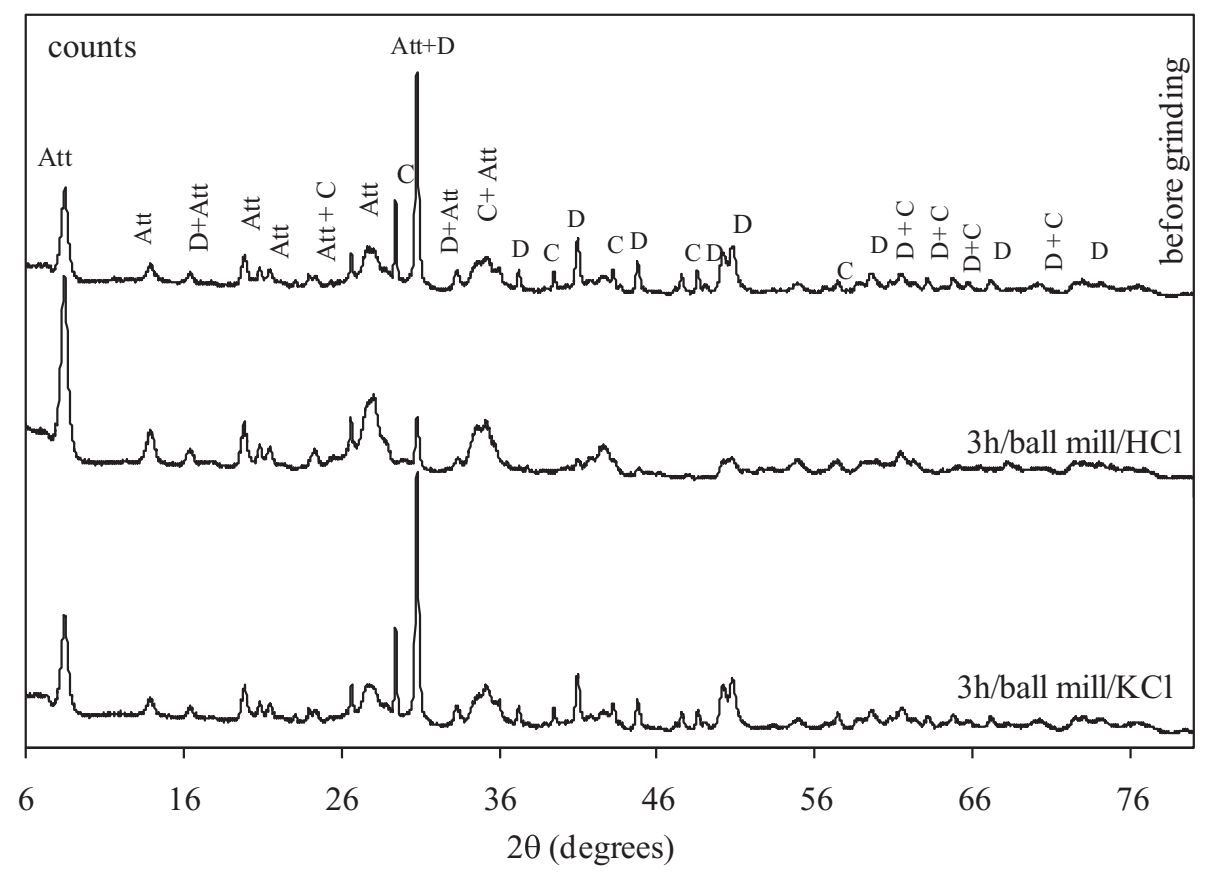

Fig. 5. X-ray diffraction patterns of attapulgite before and after $3 \mathrm{~h}$ of grinding in ball mill in $[\mathrm{HCl}]=0.5 \mathrm{M}$, and $[\mathrm{KCl}]=1 \mathrm{M}($ Att $=$ attapulgite, $\mathrm{C}=$ calcite, $\mathrm{D}=$ dolomite).

irreversible adsorption on the surface of the solid demonstrated by irreversibility indexes (Table 4) greater than $10 \%$ is one of the reasons leading to lower specific surfaces. On the other hand, the uncertainty on the actual molecular areas of organic probes must be considered, since the values were computed from adsorption isotherm data "on nonporous solids" which is not the case of the attapulgite. The gap can also be explained by structures of the probes (polarity and steric encumbrances) [21].

As for the main characteristic diameters of the attapulgite particles after grinding in ethanol and toluene, the values of the specific surfaces areas obtained after grinding in these same solvents are of the same order (105 or $100 \mathrm{~m}^{2} / \mathrm{g}$ respectively with $\mathrm{N}_{2}$ or octane for grinding in toluene compared to 100 or $90 \mathrm{~m}^{2} / \mathrm{g}$ respectively with $\mathrm{N}_{2}$ or octane for grinding in ethanol).

In a similar study on a fibrous material (chrysotile) grinded in toluene and methanol [15], a large difference was observed in the values of the specific surface areas between both solvents. It was found that the initial milling rate was $20 \mathrm{~m}^{2} / \mathrm{g} / \mathrm{h}$ and $5 \mathrm{~m}^{2} / \mathrm{g} / \mathrm{h}$ in toluene and methanol, respectively. Toluene would be a much more effective grinding agent than methanol. A link has been established by Roland with the characteristic parameters (Table 5) of the organic solvents, in particular the solubility parameter $\delta$ defining the solvent spreading capacity on the surface of a solid according to Rehbinder [29].

Thus, the higher the solubility parameter (high cohesion between solvent molecules) is, the less effective the solvent as grinding agent is. According to Rehbinder [29], an effective agent must necessarily be in contact with the fracture front. Thus, when chrysotile is grinded, toluene having a lower solubility parameter than ethanol is more effective making possible to achieve a higher milling efficiency reflected by finer particle sizes.

In the case of attapulgite grinding in ethanol and toluene and despite the different solubility parameters values of the two solvents (Table 5), particle sizes (Table 1 ) and specific surfaces are (Table 4 ) are of the same order. To explain the absence of differences during grinding in the presence of toluene or ethanol and to understand the interactions developed by these solvents on surface attapulgite, measurements of static contact angles were carried out. This technique consists to deposit a drop of liquid on a solid in the presence of vapor of the liquid. The tendency of the liquid to spread over a solid surface is estimated by the contact angle between the solid and the liquid.

With both solvents, the contact angles were equal to zero before and after compression to make compacts for analysis, which means that the two liquids spread spontaneously and perfectly wet the surface of the attapulgite. This can explain the absence of difference after grinding in these two solvents, contrary to the study carried out on chrysotile [15], since the surface increases from $15 \mathrm{~m}^{2} / \mathrm{g}$ to $66 \mathrm{~m}^{2} / \mathrm{g}$ after $24 \mathrm{~h}$ of grinding and then significantly decreases to $20 \mathrm{~m}^{2} / \mathrm{g}$ after $30 \mathrm{~h}$ of milling in toluene.

However, during wet milling in toluene and ethanol, the specific surfaces areas obtained remain as in the case of the dry ground samples, lower than those measured for the raw sample. The decrease is probably due to the modifications created in the internal structure of the attapulgite in particular the reduction of the microporous volumes (Table 2).

3.5.2.1.2. Grinding in water. The influence of grinding time was also examined in water, often used in various clays applications. The specific

Table 2

Values of specific surfaces areas $\left(\mathrm{a}_{\mathrm{BET}}\right)$, BET constants $\left(\mathrm{C}_{\mathrm{BET}}\right)$, microporous $\left(\mathrm{V}_{\text {micro }}\right)$ and mesoporous $\left(\mathrm{V}_{\text {meso }}\right)$ volumes, of attapulgite ground in wet ways obtained with nitrogen adsorption.

\begin{tabular}{|c|c|c|c|c|c|}
\hline & & $\begin{array}{l}\mathrm{a}_{\mathrm{BET}} \mathrm{N}_{2} \\
\left(\mathrm{~m}^{2} / \mathrm{g}\right) \\
\pm 0,3\end{array}$ & $\mathrm{C}_{\mathrm{BET}}$ & $\begin{array}{l}\mathrm{V}_{\text {meso }} \\
\left(\mathrm{cm}^{3} / \mathrm{g}\right) \\
\mathrm{BJH}\end{array}$ & $\begin{array}{l}V_{\text {micr }} \\
\left(\mathrm{cm}^{3} / \mathrm{g}\right) \\
\text { t-plot }\end{array}$ \\
\hline \multicolumn{2}{|c|}{ Before grinding } & 125.1 & 436 & 0.302 & 0.018 \\
\hline \multirow{2}{*}{$\begin{array}{l}\text { Organic } \\
\text { media }\end{array}$} & $3 \mathrm{~h} / \mathrm{ethanol}$ & 99.6 & 104 & 0.489 & 0.003 \\
\hline & $3 \mathrm{~h} /$ toluene & 104.9 & 151 & 0.464 & 0.007 \\
\hline \multirow{6}{*}{$\begin{array}{l}\text { Mineral } \\
\text { media }\end{array}$} & $3 \mathrm{~h} /$ water & 102.2 & 187 & 0.461 & 0.008 \\
\hline & $8 \mathrm{~h} /$ water & 84.5 & 183 & nd & nd \\
\hline & $30 \mathrm{~h} /$ water & 88.6 & 448 & nd & nd \\
\hline & $3 \mathrm{~h} / \mathrm{KCl} 1 \mathrm{M}$ & 83.9 & 193 & nd & nd \\
\hline & $\begin{array}{l}3 \mathrm{~h} / \mathrm{HCl} 0.5 \mathrm{M} \\
\text { /grinding }\end{array}$ & 177.8 & 299 & 0.666 & 0.025 \\
\hline & $\begin{array}{l}3 \mathrm{~h} / \mathrm{HCl} 0.5 \mathrm{M} \\
\text { /stirring }\end{array}$ & 158.7 & 537 & nd & nd \\
\hline
\end{tabular}

nd: not determined. 
Values of $\gamma_{s}^{\mathrm{d}}, I_{M}\left(X_{t}\right)$ and $\mathrm{I}_{\mathrm{sp}}$ of attapulgite milled in wet ways, obtained by IGC-ID at $130{ }^{\circ} \mathrm{C}$.

\begin{tabular}{|c|c|c|c|c|c|c|c|}
\hline & & \multirow{2}{*}{$\frac{\gamma_{\mathrm{s}}^{\mathrm{d}}\left(\mathrm{mJ} / \mathrm{m}^{2}\right)}{\mathrm{C} 5, \mathrm{C} 6, \mathrm{C} 7}$} & \multicolumn{3}{|l|}{$I_{M}\left(X_{t}\right)$} & \multicolumn{2}{|c|}{$\mathrm{I}_{\mathrm{sp}}(\mathrm{kJ} / \mathrm{mol})$} \\
\hline & & & 2,3,4-TMP & 2,5-DMH & Cycl-8 & $\mathrm{CH}_{2} \mathrm{Cl}_{2}$ & $\mathrm{CHCl}_{3}$ \\
\hline & & $\pm 4 \%$ & $\pm 0.03 \%$ & $\pm 0.11 \%$ & $\pm 0.01 \%$ & $\pm 1 \%$ & $\pm 1 \%$ \\
\hline \multicolumn{2}{|l|}{ Before grinding } & 164 & 0.69 & 0.67 & 0.22 & 17 & 14 \\
\hline \multirow[t]{2}{*}{ Organic media } & $3 \mathrm{~h} /$ ethanol & 123 & 0.88 & 0.76 & 0.35 & 15 & 12 \\
\hline & $3 \mathrm{~h} /$ toluene & 150 & 0.68 & 0.64 & 0.22 & 16 & 13 \\
\hline \multirow[t]{6}{*}{ Mineral media } & 3 h/water & 162 & 0.61 & 0.64 & 0.20 & 18 & 14 \\
\hline & $8 \mathrm{~h} /$ water & 152 & 0.67 & 0.68 & 0.22 & 17 & 14 \\
\hline & $30 \mathrm{~h} /$ water & 155 & 0.64 & 0.63 & 0.22 & 17 & 15 \\
\hline & $3 \mathrm{~h} / \mathrm{HCl} 0.5 \mathrm{M} / \mathrm{milling}$ & 139 & 0.74 & 0.71 & 0.25 & 17 & 13 \\
\hline & $3 \mathrm{~h} / \mathrm{HCl} 0.5 \mathrm{M} /$ stirring & 163 & 0.71 & 0.70 & 0.2 & 16 & 13 \\
\hline & $3 \mathrm{~h} / \mathrm{KCl} 1 \mathrm{M}$ & 151 & 0.61 & 0.66 & 0.21 & 16 & 13 \\
\hline
\end{tabular}

surface areas values and the BET constants determined for the different probes when grinding in water are gathered in Table 4.

The values of the nitrogen-specific surface areas decrease when the grinding time increases from $3 \mathrm{~h}$ to $8 \mathrm{~h}\left(102\right.$ to $\left.85 \mathrm{~m}^{2} / \mathrm{g}\right)$, and remain quite stable after $8 \mathrm{~h}\left(89 \mathrm{~m}^{2} / \mathrm{g}\right)$ contrary to the values obtained by IGC-FC which remain stable from $3 \mathrm{~h}$ to $8 \mathrm{~h}\left(85 \mathrm{~m}^{2} / \mathrm{g}\right.$ on average for octane and $64 \mathrm{~m}^{2} / \mathrm{g}$ for isopropanol), followed by a significant decrease after $30 \mathrm{~h}$ of grinding $\left(72 \mathrm{~m}^{2} / \mathrm{g}\right.$ for octane and $45 \mathrm{~m}^{2} / \mathrm{g}$ for isopropanol). Grinding studies in water [14] on another type of clay, muscovite mica, have shown that the specific surface area of this lamellar solid increases even up to $75 \mathrm{~h}$ of grinding in the ball mill. This development is explained by the mechanical stresses favoring the formation of very active lateral surfaces.

As for chrysotile, Roland [10] showed that despite very long grinding times in water, the surface of the fibers continues to increase. After $120 \mathrm{~h}$ of grinding in water, the chrysotile still has a fibrillar structure and the specific surface area varies from $15 \mathrm{~m}^{2} / \mathrm{g} 90 \mathrm{~m}^{2} / \mathrm{g}$ meaning defibrillation of chrysotile in an aqueous medium. The great resistance to amorphization during the grinding of chrysotile in aqueous medium is explained by the theory of Westwood [30] according to which there exists a film of protective water acting as a lubricant or shield towards mechanical stresses.

Vucelic [12] in its study of sepiolite grinding in aqueous medium found significant changes in the surface area. Indeed, it decreases from $243 \mathrm{~m}^{2} / \mathrm{g}$ to $140 \mathrm{~m}^{2} / \mathrm{g}$, meaning that the structure of the fibers of the sepiolite undergoes changes during grinding in water attributed by the author to the decrease in the number of micropores caused by partial amorphization affecting the surface of the fibers of the sepiolite.

Table 4

Values of the specific surface areas $\left(\mathrm{a}_{\mathrm{BET}}\right)$, BET constants $\left(\mathrm{C}_{\mathrm{BET}}\right)$ and irreversibility indexes $\left(\mathrm{I}_{\text {irr }}\right)$ of attapulgite before and after grinding in organic media, in water, in $\mathrm{KCl}(1 \mathrm{M})$ and in acid media, obtained by nitrogen adsorption and IGC-FC (with octane C8 and isopropanol IP).

\begin{tabular}{|c|c|c|c|c|c|c|c|c|}
\hline & \multirow{2}{*}{\multicolumn{2}{|c|}{$\begin{array}{l}\text { Adsorption } \\
\mathrm{N}_{2}\end{array}$}} & \multicolumn{6}{|l|}{ IGC-FC } \\
\hline & & & \multicolumn{3}{|c|}{$\mathrm{C} 8\left(53{ }^{\circ} \mathrm{C}\right)$} & \multicolumn{3}{|c|}{$\operatorname{IP}\left(43^{\circ} \mathrm{C}\right)$} \\
\hline & $\begin{array}{l}\mathrm{a}_{\mathrm{BET}} \\
\left(\mathrm{m}^{2 / \mathrm{g}}\right)\end{array}$ & $\begin{array}{l}\mathrm{C} \\
\mathrm{BET}\end{array}$ & $\begin{array}{l}\mathrm{a}_{\mathrm{BET}} \\
\left(\mathrm{m}^{2} / \mathrm{g}\right)\end{array}$ & $\begin{array}{l}\text { C } \\
\text { BET }\end{array}$ & $\begin{array}{l}\mathrm{I}_{\mathrm{irr}} \\
(\%)\end{array}$ & $\begin{array}{l}\mathrm{a}_{\mathrm{BET}} \\
\left(\mathrm{m}^{2} / \mathrm{g}\right)\end{array}$ & $\mathrm{C}_{\mathrm{BET}}$ & $\begin{array}{l}\mathrm{I}_{\mathrm{irr}} \\
(\%)\end{array}$ \\
\hline & \pm 0.3 & & \pm 2.8 & & \pm 0.2 & \pm 4 & & \pm 0.6 \\
\hline Before grinding & 125.1 & 437 & 114.5 & 9 & 0.6 & 71 & 22 & 8.3 \\
\hline $3 \mathrm{~h} /$ toluene & 104.9 & 151 & 100.6 & 8 & 1.1 & 69 & 18 & 17.5 \\
\hline $3 \mathrm{~h}$ /ethanol & 99.6 & 104 & 89.7 & 8 & 1.3 & 60 & 24 & 14.7 \\
\hline $3 \mathrm{~h} /$ water & 102.2 & 187 & 81.4 & 8 & 0.8 & 64 & 19 & 14.5 \\
\hline 8 h/water & 84.5 & 183 & 88.9 & 10 & 1.3 & 63 & 23 & 13.1 \\
\hline $30 \mathrm{~h} /$ water & 88.6 & 448 & 71.8 & 10 & 1.0 & 45 & 27 & 18.7 \\
\hline $3 \mathrm{~h} / \mathrm{KCl} 1 \mathrm{M}$ & 83.9 & 193 & 89.5 & 10 & 1.7 & 73 & 23 & 11.7 \\
\hline $3 \mathrm{~h} / \mathrm{HCl} 0.5 \mathrm{M}$ grinding & 177.8 & 296 & 155.9 & 12 & 1.7 & 114 & 19 & 11.8 \\
\hline $3 \mathrm{~h} / \mathrm{HCl} 0.5 \mathrm{M}$ stirring & 158.7 & 535 & 125.2 & 9 & 2.7 & 97 & 21 & 14 \\
\hline
\end{tabular}

3.5.2.1.3. Grinding in the $\mathrm{KCl}$ solution. The introduction of potassium ions into the grinding medium can result in a process of exchanging these ions with the other cations attached to the surface of the fibers. Indeed, the cations on the surface of a solid have the possibility of exchanging with those contained in the surrounding solution according to their degree of affinity. The ion exchange process can modify the electrostatic interactions between separated particles and influence the grinding process of the attapulgite fibers. Thus, a grinding experiment was carried out in a $1 \mathrm{M} \mathrm{KCl}$ solution. The specific surfaces areas obtained with octane, $89.5 \mathrm{~m}^{2} / \mathrm{g}$, and with nitrogen, $83.9 \mathrm{~m}^{2} / \mathrm{g}$, decrease compared to 114.5 and $125.1 \mathrm{~m}^{2} / \mathrm{g}$ respectively before grinding (Table 4). The modifications created in the internal structure of attapulgite, in particular the reduction of active sites such as the micoporous volume and the decrease in repulsive forces leading to agglomeration may explain the reduction in the specific surface area.

The similarity of diameters values (Table 1) and the simultaneous differences in specific surface areas (Table 2) observed between experiments using $\mathrm{KCl}$ or only $\mathrm{H}_{2} \mathrm{O}$ for the same grinding time ( $3 \mathrm{~h}$ ), could be explained by the modifications of the internal surface of particles (porosity) which predominates compared to the external surface, modifications probably due to the combined effects of compression at moment of grinding (relatively slow rotational speed) and influence on the surface interactions due to the medium $\mathrm{H}_{2} \mathrm{O}$ or $\mathrm{KCl}$ (less repulsion in the presence of $\mathrm{KCl}$ ). However, this assumption requires more investigation to be proved.

With isopropanol no change was observed demonstrating that the surface chemistry of the milled solid is not sensitive to mechanical stresses under these grinding conditions.

Table 5

Characteristic parameters of used solvents.

\begin{tabular}{lll}
\hline Liquid & Surface energy & Solubility parameter \\
\cline { 2 - 2 } & $\gamma_{\mathrm{L}}\left(\mathrm{mJ} \cdot \mathrm{m}^{-2}\right)$ & $\delta$ \\
\hline Toluene & 28.4 & 8.9 \\
Methanol & 22.6 & 14.5 \\
Ethanol & 22.8 & 12.7 \\
\hline
\end{tabular}

Table 6

Concentrations in $(\mathrm{mg} / \mathrm{L})$ of the elements present in the filtrates obtained after grinding in water and in $0.5 \mathrm{M} \mathrm{HCl}$ solution determined by ICP.

\begin{tabular}{llll}
\hline & With stirring in $\mathrm{HCl} 0.5 \mathrm{M}$ & $3 \mathrm{~h}$ /grinding in water & $3 \mathrm{~h}$ /grinding in $\mathrm{HCl} 0.5 \mathrm{M}$ \\
\hline $\mathrm{Al}$ & 0.013 & 0.2 & 7.03 \\
$\mathrm{Ca}$ & 0.313 & 31.3 & 437.83 \\
$\mathrm{~K}$ & 0.045 & 28.8 & 65.64 \\
$\mathrm{Mg}$ & 0.035 & 59.1 & 391.3 \\
$\mathrm{Si}$ & 0.157 & 9.8 & 40.68
\end{tabular}





Fig. 6. Distribution functions of the adsorption energies with n-octane (a) and isopropanol, and (b) of attapulgite before and after grinding in organic media.

3.5.2.1.4. Grinding in $\mathrm{HCl}$ acid medium. The values of the specific surfaces areas and the BET constants determined for the various probes during grinding or under simple stirring in an acid medium, are gathered in Table 4.

Unlike all the other media mentioned above, in an acid medium the specific surface area obtained after grinding increases whatever the probe injected. This specific surface area increase is accompanied by the increases of meso and microporous volumes (Table 2), from $0.30 \mathrm{~cm}^{3} / \mathrm{g}$ before grinding to $0.66 \mathrm{~cm}^{3} / \mathrm{g}$ and $0.018 \mathrm{~cm}^{3} / \mathrm{g}$ to $0.025 \mathrm{~cm}^{3} /$ $\mathrm{g}$ respectively. These variations are attributed to the acid attack of the carbonates already observed by SEM (Fig. 2). These are partially eliminated as confirmed by the ICP analysis of the filtrates obtained after grinding (Table 6). In addition to the removal of calcium, other ions, including magnesium are collected in the filtrates after grinding, an evidence of the alteration of the crystalline structure of attapulgite.

The specific surfaces areas determined with the three probes of the sample simply stirred in a solution of $0.5 \mathrm{M} \mathrm{HCl}$ acid showed high values compared to the raw attapulgite but remained lower than those determined after grinding in the same environment. The highest amounts of calcium ions are obtained in the filtrates after grinding in an acid medium. These results reinforce those obtained by IGC-ID and make it possible to conclude that the coupling: mechanical stresses/grinding medium at low $\mathrm{pH}$ is therefore necessary for the improvement of the surface properties of the attapulgite in particular the specific surface area, since, it seems to be able to generate new surfaces unlike other grinding media.
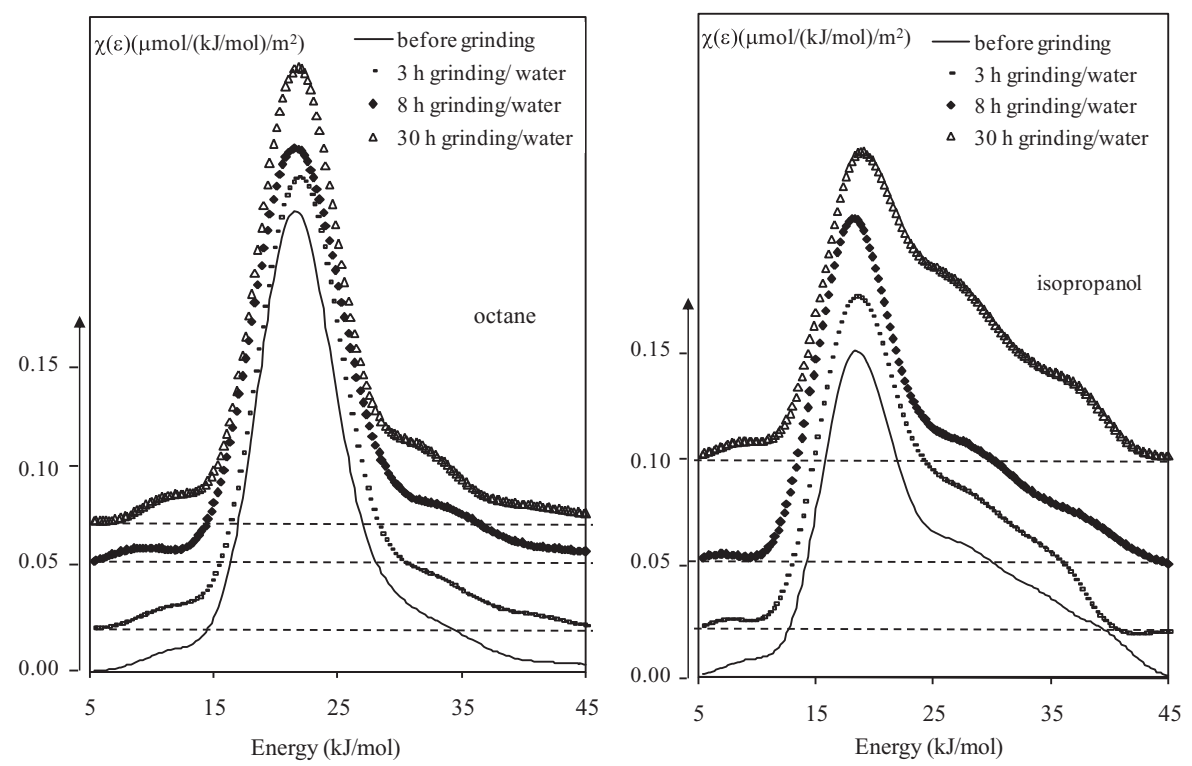

Fig. 7. Distribution functions of the adsorption energies with n-octane (a) and isopropanol, and (b) of attapulgite before and after grinding in water at different times. 

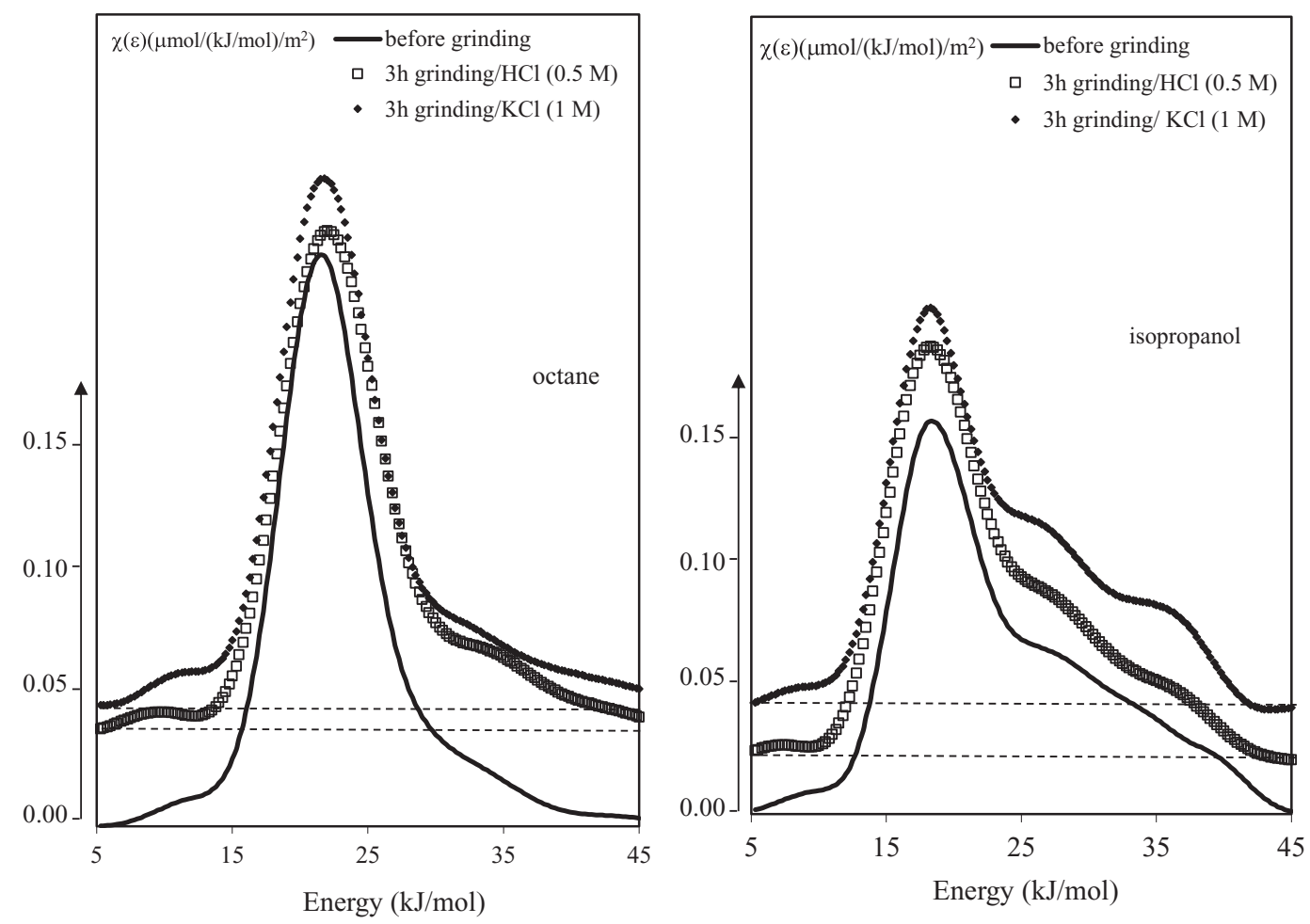

Fig. 8. Distribution functions of the adsorption energies with n-octane (a) and isopropanol, and (b) of attapulgite before and after grinding in mineral media.

3.5.2.2. Evolution of surface heterogeneity. Figs. 6,7 and 8 shows the influence of grinding in liquid media (organic and inorganic) in the ball mill on the energy distribution functions of the attapulgite adsorption sites, obtained with the two probes, n-octane and isopropanol.

For octane, the monomodal DF don't vary after grinding. Unlike the DF obtained with the isopropanol probe, which appears more sensitive to surface modifications under grinding. The asymmetrical peak observed before grinding evolves towards a trimodal function with a main peak centered on $20 \mathrm{~kJ} / \mathrm{mol}$ and two other ones at 25 and $35 \mathrm{~kJ} /$ mol, evidence of the appearance, after grinding, of polar sites able to interact with the isopropanol probe. The detachment of some fibers in the porous network during grinding, may be responsible for the formation of new sites, such as hydroxyl function. According to the literature $[13,31]$, the peak towards low energies reflect the hydrogen interactions between the alcohol function of the isopropanol probe and siloxane groups $(\mathrm{Si}-\mathrm{O}-\mathrm{Si}$ ) on the solid surface of attapulgite, whereas the peaks at high energy can be attributed to stronger interactions through hydrogen bound of the probe with the silanol groups on the solid.

\section{Conclusion}

This study highlights the performance of attapulgite wet grinding, and put forward, through the obtained results, some advantages over the dry way, such as, possibility to achieve finer particle sizes than with dry grinding, possibility to avoid agglomeration of particles over long grinding times and allows to preserve the fibrous morphology of attapulgite, especially in the aqueous medium, even during a prolonged grinding time.

The grinding-acid medium coupling, is distinguished from other grinding media (aqueous solution and solvent). Thus, the low $\mathrm{pH}$ value of the medium associated with mechanical stress improves the attapulgite surface properties and in particular its surface area which increases significantly.

The grinding affects poorly the distribution functions regardless of the grinding media despite the fineness of the particles obtained. In fact, fragmentation generates few surfaces due to the disordered fibrous structure of attapulgite and gives it a high elasticity favoring the dissipation of the grinding energy.

\section{Declaration of Competing Interest}

The authors declare that they have no known competing financial interests or personal relationships that could have appeared to influence the work reported in this paper.

\section{Acknowledgments}

This research was carried out at RAPSODEE, a research center of IMT Mines Albi, as part of the implementation of the residential training program abroad.

\section{References}

[1] K.A. Carrado, P. Komadel, Acid activation of bentonites and polymer-clay nanocomposites, Miner. Soc. Am. 5 (2009).

[2] S.N.A. Muttalib, N. Othman, Effect of ball milling parameters on properties of attapulgite fillednaturalrubber composite, Proc. Chem. 19 (2016) 381-387.

[3] A. Purohit, S. Chander, A. Hameed, P. Singh, M.S. Dhaka, Structural, dielectric and surface morphological properties of ball clay with wet grinding for ceramic electrical insulators, Mater. Chem. Phys. 181 (2016) 359-366.

[4] X. Cao, D. Chen, H. Gu, A. Huang, H. Ni, Improved bonding properties of rectorite clay slurry afterwet/dry grinding, Appl. Clay Sci. 183 (2019), 105318.

[5] A. Neaman, A. Singer, Possible use of the Sacalum (Yucatan) palygorskite as drilling muds, Appl. Clay Sci. 25 (2004) 121-124.

[6] A. López-Galindo, C. Viseras, P. Cerezo, Compositional, technical and safety specifications of clays to be used as pharmaceutical and cosmetic products, Appl. Clay Sci. 36 (2007) 51-63.

[7] C. Viseras, C. Aguzzi, P. Cerezo, A. Lopez-Galindo, Uses of clay minerals in semi solid health care and therapeutic products, Appl. Clay Sci. 36 (2007) 37-50.

[8] C. Blachier, L. Michot, I. Bihannic, O. Barrès, A. Jacquet, M. Mosquet, Adsorption of polyamine on clay minerals, J. Colloid Interf. Sci. 336 (2009) 599-606.

[9] G. Delubac, Société de l'Industrie Minérale, Broyage, 19969.

[10] P. Roland, Contribution à l'étude du broyage des amiantes et du mica muscovite, PhD Thesis University of Haute-Alsace, 1986. 
[11] O. Aouadj, Etude du broyage humide de la muscovite influence d'additifs de broyage acryliques: l'acide polyacrylique et ses oligomères, $\mathrm{PhD}$ Thesis University of Haute Alsace, 1994.

[12] D. Vucelic, D. Simic, O. Kovacevic, M. Dojcinova, M. Mitrovic, The effects of grinding on the physicochemical characteristics of white sepiolite from Golesh, J. Serb. Chem. Soc. 67 (2002) 197-211.

[13] H. Balard, E. Brendlé, E. Papirer, Determination of the acid-base properties of solid surfaces using Inverse Gas Chromatography:Advantages and limitations, in: K. Mittal (Ed.), Acid-Base Interactions, Relevance to Adhesion Science and Technology, VSP, Utrecht, The Netherlands 2000, pp. 299-316.

[14] H. Balard, O. Aouadj, E. Papirer, Monitoring by inverse gas chromatography, of the variation of the surface energetic heterogeneity of ground muscovite samples, Langmuir 13 (1997) 1251-1255.

[15] E. Papirer, P. Roland, Grinding of chrysotile in hydrocarbons, alcohol, and water, Clay Clay Miner. 29 (1981) 161-170.

[16] E. Papirer, P. Roland, M. Nardin, H. Balard, Variation of the surface energy characteristics of mica (muscovite) upon grinding, J. Colloid Interf. Sci. 113 (1986) 62-66.

[17] H. Balard, D. Maafa, A. Santini, J.B. Donnet, Study by inverse gas chromatography of the surface properties of milled graphites, J. Chromatogr. A 1198-1199 (2008) $173-180$.

[18] W.F. Bradley, The structural scheme of attapulgite, Am. Mineral. 25 (1940) 405-410.

[19] A. Chahi, S. Petit, A. Decarreau, Infrared evidence of dioctahedral-trioctahedral site occupancy in palygorskite, Clay Clay Miner. 50 (2002) 306.

[20] M. Suarez, E. Garcia-Romero, FTIR spectroscopic study of palygorskite: influence of the composition of the octahedral sheet, Appl. Clay Sci. 31 (2006) 154-163.

[21] L. Boudriche, A. Chamayou, R. Calvet, B. Hamdi, H. Balard, Influence of different dry grinding processes on the properties of an attapulgite clay, contribution of inverse gas chromatography, Powder Technol. 254 (2014) 352-363.
[22] J.R. Conder, C.L. Young, Physicochemical Measurements by Gas Chromatography, WileyInterscience, New York, 1979 385-390.

[23] G.M. Dorris, D.G. Gray, Adsorption, spreading pressure and London force interactions of hydrocarbons on cellulose and wood fiber surfaces, J. Colloid Interf. Sci. 71 (1979) 93-104.

[24] E. Brendlé, E. Papirer, A new topological index for molecular probes used in inverse gas chromatography for the surface nanorugosity evaluation, J. Colloid Interf. Sci. 194 (1997) 207-216.

[25] E. Morales, M.V. Dabrio, C.R. Herrero, J.L. Acosta, Acid/base characterization of sepiolite by inverse gas chromatography, Chromatographia 31 (1991) 357-361.

[26] A. Askin, D. TopalogluYazici, Surface characterization of sepiolite by inverse gas chromatography, Chromatographia 61 (2005) 625-631.

[27] S. Lazarević, Z. Radovanović, D.J. Veljović, A. Onjia, D.J. Janaćković, R. Petrović, Characterization of sepiolite by inverse gas chromatography at infinite and finite surface coverage, Appl. Clay Sci. 43 (2009) 41-48.

[28] H. Balard, A. Saada, J. Hartmann, O. Aouadj, E. Papirer, Estimation of the surface energetic heterogeneity of fillers by inverse gas chromatography, Macromol. Symp. 108 (1996) 63-80.

[29] P.A. Rehbinder, L.A. Schreiner, K.F. Zhigach, Hardnessreducers in Drilling, Trans Council of Scientific and Industrial Research, Melbourne, 1948 163-172.

[30] A.R.C. Westwood, R.M. Latanison, Surface and environmental effects in deformation, Mater. Sci. Eng. 25 (1976) 225-231.

[31] E. Papirer, H. Balard, C. Vergelati, Surface energetics of silica investigated by inverse gas chromatography, Surfactant Science, Adsorption on Silica Surfaces, vol. 90, Marcel Dekker Inc, New York 2000, pp. 205-242. 